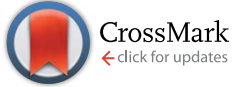

Cite this: RSC Adv., 2017, 7, 461

Received 5th October 2016 Accepted 29th November 2016

DOI: $10.1039 / c 6 r a 24780 f$

www.rsc.org/advances

\section{A study of the interaction between inverted cucurbit[7]uril and symmetric viologens $\uparrow$}

\author{
Zhongzheng Gao, ${ }^{a}$ Dong Bai, ${ }^{a}$ Lixia Chen, ${ }^{a}$ Zhu Tao, ${ }^{a}$ Xin Xiao, ${ }^{\text {*a }}$ Timothy J. Prior ${ }^{b}$ \\ and Carl Redshaw ${ }^{\star b}$
}

The interaction between inverted cucuribit[7]uril (iQ[7]) and a series of symmetric viologen derivatives bearing aliphatic substituents of variable length, namely dicationic dialkyl-4,4'-bipyridinium guests where the alkyl is $\mathrm{CH}_{3}\left(\mathrm{CH}_{2}\right)_{n}$ with $n=0$ to 6 , has been studied in aqueous solution by ${ }^{1} \mathrm{H}$ NMR spectroscopy, electronic absorption spectroscopy, isothermal titration calorimetry and mass spectrometry. In the case of both $n=5\left(\mathrm{HV}^{2+}\right)$ and $6\left(\mathrm{SV}^{2+}\right)$, single crystal X-ray diffraction revealed the composition to be [(iQ $\left.[7])_{2}(\mathrm{HV})_{2}\right]\left[\mathrm{CdCl}{ }_{3} \mathrm{Br}\right]\left[\mathrm{H}_{3} \mathrm{O}^{+}\right]_{2}\left[\mathrm{H}_{2} \mathrm{O}\right]_{12.5}$ and $(\mathrm{iQ}[7])_{2}(\mathrm{C} 7-\mathrm{SV})_{1.5}\left[\mathrm{CdCl}_{4}\right]_{4}\left(\mathrm{H}_{3} \mathrm{O}^{+}\right)_{5}\left(\mathrm{H}_{2} \mathrm{O}\right)_{8}$, respectively, with both adopting an external $\mathrm{B}$-type structure (the alkyl chains of the viologen reside within the iQ[7]).

\section{Introduction}

Although the chemistry of cucurbit[n]urils continues to flourish, ${ }^{1}$ that of the related inverted cucurbit $[n]$ urils is at an embryonic stage. ${ }^{2}$ We are interested in developing the hostguest/inclusion properties of such species for useful applications. With this in mind, we are interested in the ability of inverted cucurbit $[n]$ urils to include viologens, which are of potential use in electrochromic displays. ${ }^{3}$ In the case of the cucurbit[7]uril system $(\mathrm{Q}[7])$, work by the group of Kaifer over a decade ago reported studies on the binding interaction between $\mathrm{Q}[7]$ and viologen hosts. ${ }^{4-7}$ In particular, they examined the inclusion of $4,4^{\prime}$-pyridinium dicationic guests, measured the binding constants (typically $1 \times 10^{9} \mathrm{~L} \mathrm{~mol}^{-1}$ ) and investigated the effect that one electron reduction of the viologen had on the binding constants. ${ }^{4}$ Work was also extended to the cucurbit[8] uril system $(\mathrm{Q}[8]),{ }^{8}$ whilst viologens covalently bonded to Newkome-type dendritic structures have been encapsulated by

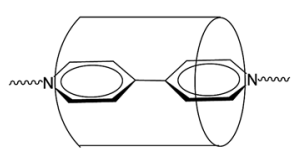

$\mathbf{A}$

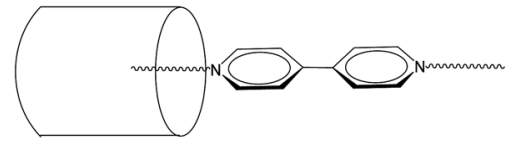

B

Scheme 1 A-Type structure (a pseudo-rotaxane inclusion complex) B-type structure (an external structure).

${ }^{a}$ Key Laboratory of Macrocyclic and Supramolecular Chemistry of Guizhou Province, Guizhou University, Guiyang 550025, China.E-mail: gyhxxiaoxin@163.com

${ }^{b}$ Department of Chemistry, University of Hull, Hull HU6 7RX, UK. E-mail: C.Redshaw@hull.ac.uk

$\dagger$ Electronic supplementary information (ESI) available. CCDC 1505620 and 1505621. For ESI and crystallographic data in CIF or other electronic format see DOI: $10.1039 / \mathrm{c} 6 \mathrm{ra} 24780 \mathrm{f}$
$\mathrm{Q}[7]$. Of more relevance to the work herein are the investigations into the effects of varying the aliphatic chain lengths in dialkyl4,4'-bipyridinium dicationic guests on interaction with $\mathrm{Q}[7]{ }^{9}{ }^{9}$ Two types of structures were identified (see Scheme 1): in A, a pseudorotaxane inclusion complex is adopted whereby the bipyridinium core of the viologen is embedded in the $\mathrm{Q}[7]$ host; this structure is favoured by short N-bound substituents. In $\mathbf{B}$, which is adopted by larger ( $\geqq$ butyl) substituents, the arrangement is best described as an external structure for which the core of the viologen is not found within the host. Furthermore, an intermediate situation is observed for propyl substituents, whilst the presence of polar groups favours a pseudo-rotaxane inclusion complex..$^{10}$ More recently, the interaction of the same family of dialkyl-4, $4^{\prime}$ bipyridinium dicationic guests with cyclohexanocucurbit[6]uril and twisted cucurbit[14]uril has also been studied. ${ }^{11}$

We are interested in the properties of the inverted cucurbit [7]uril $\mathrm{iQ}[7]$ system, and have recently investigated host-guest interactions with $\alpha, \omega$-alkyldiammonium guests. ${ }^{12}$ Herein, we report for the first time the interaction of viologen derivatives, namely dialkyl-4,4'-bipyridinium dicationic guests bearing
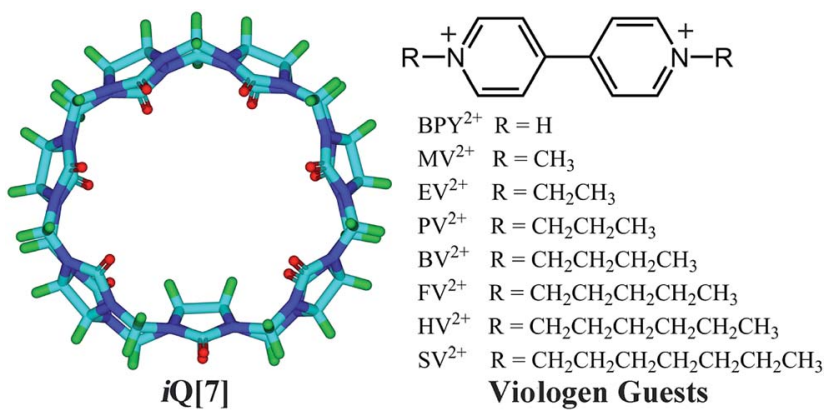

Scheme $2 \mathrm{iQ}[7]$ and the viologens employed herein. 
symmetric aliphatic chains of varying lengths with inverted cucuribit[7]uril (iQ[7]) - see Scheme 2.

\section{Results and discussion}

The host-guest chemistry was investigated in aqueous solution using ${ }^{1} \mathrm{H}$ NMR spectroscopy, which revealed that all of the dialkyl-4,4'-bipyridinium dicationic guests formed interactions with $\mathrm{iQ}[7]$, see Fig. $1 \mathrm{~A}-\mathrm{F}$. For the smaller chains $\left(\mathrm{BPY}^{2+} ; \mathrm{MV}^{2+}\right.$, $n=0 ; \mathrm{EV}^{2+}, n=1$ - see Scheme 2), there are significant changes in the positions of the $\alpha$ and $\beta$ bipy protons consistent with the adoption of type $\mathbf{A}$ structures, whereas for the longer chains $\left(\mathrm{PV}^{2+}, n=2 ; \mathrm{BV}^{2+}, n=3 ; \mathrm{FV}^{2+}, n=4 ; \mathrm{HV}^{2+}, n=5 ; \mathrm{SV}^{2+}, n=6\right)$, the positions of the bipy protons remains relatively unchanged, whilst the chain protons (a-f) experience some shift changes consistent with a type $\mathbf{B}$ structure.

The binding interactions between each of the viologen guests and $\mathrm{iQ}[7]$ can be conveniently monitored using ${ }^{1} \mathrm{H}$ NMR spectroscopic data recorded in neutral $\mathrm{D}_{2} \mathrm{O}$ solution. Fig. 1 shows the changes observed in the spectrum of $\mathrm{BPY}^{2+}$ as progressively larger amounts of $\mathrm{iQ}[7]$ are added to the solution. As the concentration of $\mathrm{iQ}[7]$ increases, the signal corresponding to the $\alpha$ and $\beta$ aromatic protons of the guest shifts up-field. Upon addition of 1 equivalent of host, the $\alpha$ protons signal shifts up-field by $0.42 \mathrm{ppm}$, while the complexation-induced shift of the signal for the $\beta$ protons is found at $0.96 \mathrm{ppm}$ at the same point in the titration with $\mathrm{iQ}[7]$. These data indicate that part of the $\mathrm{BPY}^{2+}$ is inserted into the cavity of $\mathrm{iQ}[7]$, thereby forming a $1: 1$ inclusion complex in which the bipyridinium core of the viologen nucleus is included in the cavity.

Fig. 2 shows the ${ }^{1} \mathrm{H}$ NMR spectra of $\mathrm{MV}^{2+}$ in $\mathrm{D}_{2} \mathrm{O}$ recorded in the absence (top) and in the presence of host. The most noticeable effect observed upon $\mathrm{iQ}[7]$ addition is the up-field displacement and broadening of the $\beta$ aromatic protons of the guest. Upon addition of 1.1 equivalents of host, this resonance exhibits a chemical shift of $7.35 \mathrm{ppm}$, compared to its original chemical shift of $8.40 \mathrm{ppm}$ in the absence of host. The $\alpha$ protons signal shifts up-field by $0.15 \mathrm{ppm}$, while the methyl

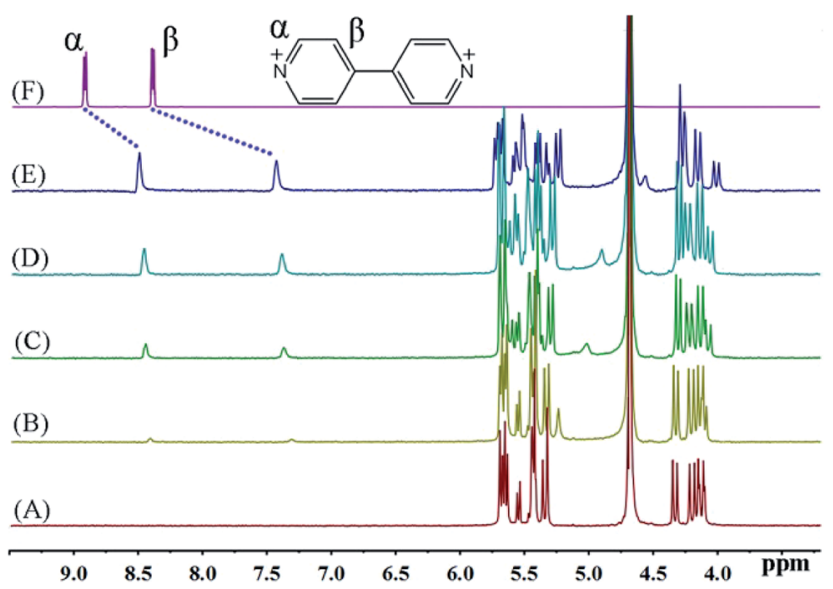

Fig. $1{ }^{1} \mathrm{H}$ NMR spectra (400 MHz, $\left.\mathrm{D}_{2} \mathrm{O}\right)$ of $\mathrm{iQ}$ [7] (A) in the absence and in the presence of (B) 0.2, (C) 0.4, (D) 0.8, (E) 1.1 equivalents of $\mathrm{BPY}^{2+}$ and $(\mathrm{F})$ neat $\mathrm{BPY}^{2+}$ in $\mathrm{D}_{2} \mathrm{O}$ at $20^{\circ} \mathrm{C}$.

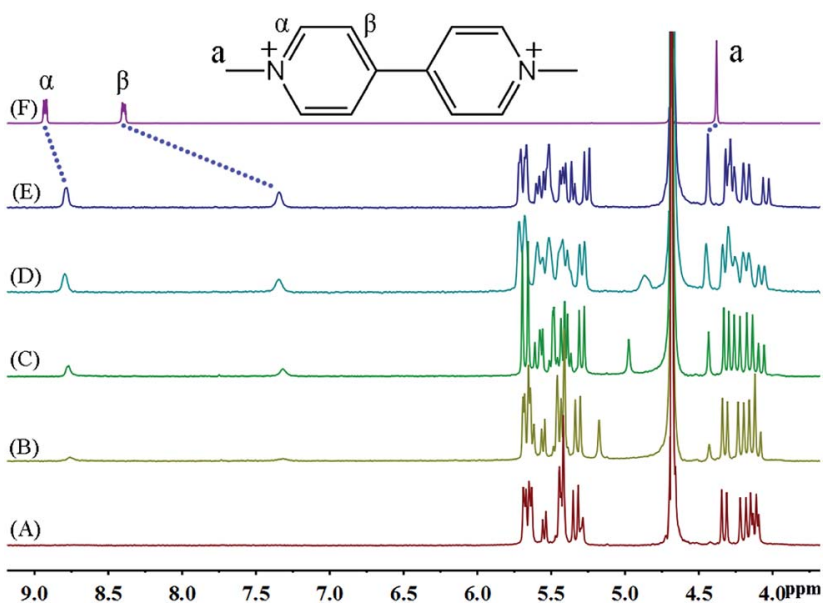

Fig. $2{ }^{1} \mathrm{H}$ NMR spectra $\left(400 \mathrm{MHz}, \mathrm{D}_{2} \mathrm{O}\right)$ of iQ[7] (A) in the absence and in the presence of (B) $0.1,(C) 0.4$, (D) 0.8 , (E) 1.1 equivalents of $\mathrm{MV}^{2+}$ and $(F)$ neat $\mathrm{MV}^{2+}$ in $\mathrm{D}_{2} \mathrm{O}$ at $20^{\circ} \mathrm{C}$.

protons signal shifts downfield by $0.06 \mathrm{ppm}$. This sizable complexation-induced shift is similar to that observed in the iQ [7]@BPY ${ }^{2+}$ inclusion complex. Given the similarity of the Q[7] complexation effects observed for the guests $\mathrm{MV}^{2+}$ and $\mathrm{EV}^{2+}$, both likely exhibit a similar mode of binding on interaction with $\mathrm{Q}[7] .^{9}$ In other words, inclusion complexation takes place with these two viologen guests in such a way that the host is fully threaded by the guest and the main binding site for the host is the aromatic viologen residue. These inclusion complexes can be considered to adopt pseudo-rotaxane type structures.

The binding behaviour between $\mathrm{iQ}[7]$ and $\mathrm{EV}^{2+}$ is also illustrated by recording the ${ }^{1} \mathrm{H}$ NMR spectra, which are shown in Fig. 3. While the overall behaviour seems at first glance to be similar to that observed with $\mathrm{MV}^{2+}$, close inspection reveals a number of differences. As shown in Fig. 3B-E, the protons of $\alpha$ and $\beta$ exhibit visible up-field shifts upon complexation with the $\mathrm{iQ}[7]$ host, indicating that the pyridine ring is included into

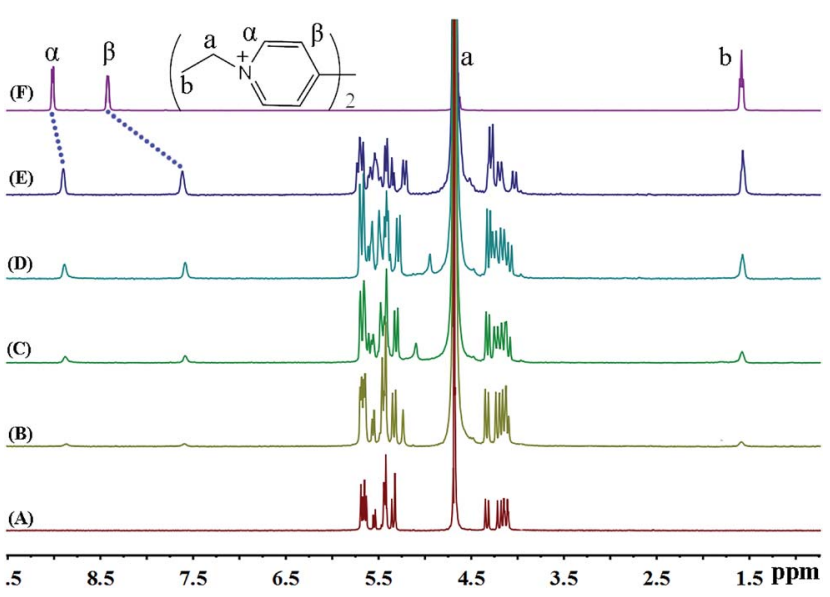

Fig. $3{ }^{1} \mathrm{H}$ NMR spectra (400 MHz, $\mathrm{D}_{2} \mathrm{O}$ ) of iQ[7] (A) in the absence and in the presence of (B) $0.1,(C) 0.3,(D) 0.5,(E) 1.0$ equivalent of $E^{2+}$ and (F) neat $\mathrm{EV}^{2+}$ in $\mathrm{D}_{2} \mathrm{O}$ at $20^{\circ} \mathrm{C}$. 
the $\mathrm{iQ}[7]$ cavities. The complexation-induced shift for the signal corresponding to the $\alpha$ aromatic protons of $\mathrm{EV}^{2+}(0.12 \mathrm{ppm})$ is smaller than that observed for $\mathrm{MV}^{2+}(0.15 \mathrm{ppm})$. The signal for the $-\mathrm{CH}_{3}$ protons does not show any significant change. As in the case of $\mathrm{MV}^{2+}$, the chemical exchange between free $\mathrm{EV}^{2+}$ and its $\mathrm{iQ}[7]$ complex is fast on the NMR time scale.

As shown in Fig. 4, the binding behaviour of iQ[7] with guest $\mathrm{BV}^{2+}$ clearly departs from our observations to-date when using $\mathrm{BPY}^{2+}, \mathrm{MV}^{2+}$ and $\mathrm{EV}^{2+}$. It is evident that the host does not induce any significant shifts in the $\beta$ aromatic protons, while the $\alpha$ aromatic protons are displaced up-field by $0.16 \mathrm{ppm}$. At the same time, the four resonances corresponding to the terminal $-\mathrm{CH}_{2} \mathrm{CH}_{2} \mathrm{CH}_{2} \mathrm{CH}_{3}$ protons on the aliphatic butyl chains undergo up-field shifts $(0.25,0.36,0.31,0.27)$. This pattern of complexation-induced shifts can be ascribed to the $\mathrm{iQ}[7]$ binding to one of the positively charged nitrogens while including the butyl chain inside its cavity. Given the symmetry associated with the viologen guests, both hosts act in a similar fashion and bind to the "outside" aliphatic docking sites instead of reaching the central viologen nucleus (Scheme 1B).

The binding interactions between $\mathrm{PV}^{2+}$ and $\mathrm{iQ}[7]$ are different from those observed in the presence of either $\mathrm{EV}^{2+}$ or $\mathrm{BV}^{2+}$. Most notably, the addition of the host $\mathrm{iQ}[7]$ causes a modest up-field shift from 8.44 to $8.38 \mathrm{ppm}$ of the resonance for the $\beta$ aromatic protons of guest $\mathrm{PV}^{2+}$. Furthermore, the peak corresponding to the $\alpha$ aromatic protons undergoes an up-field displacement (0.15 ppm), whilst the aliphatic propyl chains ( $\mathrm{a}, \mathrm{b}$ and $\mathrm{c}$ protons) are shifted significantly up-field by $0.21,0.28$ and $0.24 \mathrm{ppm}$, respectively. Upon addition of increasing amounts of the host, all the proton resonances corresponding to the aliphatic propyl chains undergo up-field shifts. The signal for the $\alpha$ aromatic protons shifts up-field, while the signal for the $\beta$ protons does not show any significant change (Fig. 5).

This behaviour can be rationalized by the inclusion of the propyl chain inside the cavity of the host, with the bipyridinium nucleus remaining outside. Only a single set of proton

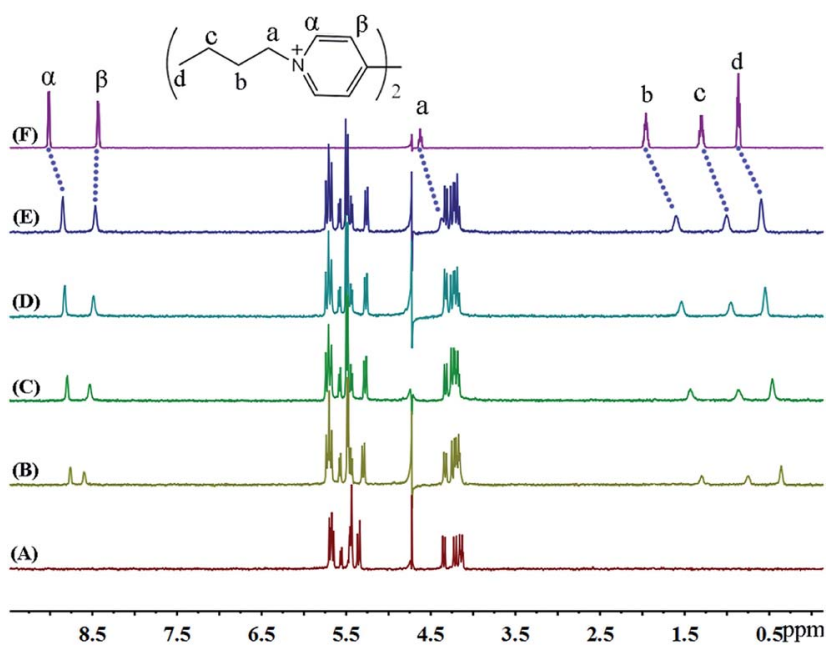

Fig. $4{ }^{1} \mathrm{H}$ NMR spectra $\left(400 \mathrm{MHz}, \mathrm{D}_{2} \mathrm{O}\right)$ of $\mathrm{iQ}[7](\mathrm{A})$ in the absence and in the presence of (B) 0.6, (C) 1.0, (D) 1.6, (E) 2.1 equivalents of $\mathrm{BV}^{2+}$ and (F) neat $\mathrm{BV}^{2+}$ in $\mathrm{D}_{2} \mathrm{O}$ at $20^{\circ} \mathrm{C}$.

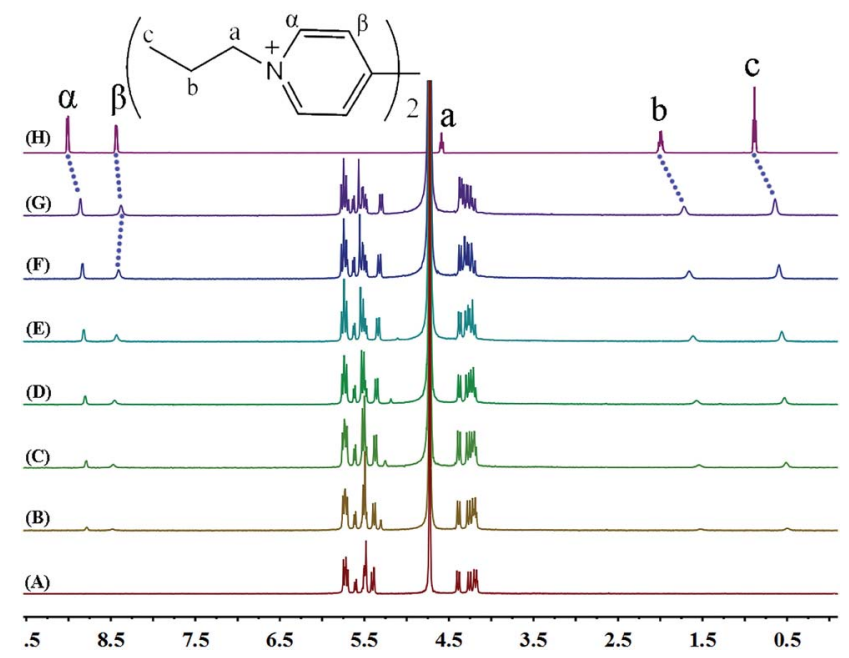

Fig. $5{ }^{1} \mathrm{H}$ NMR spectra $\left(400 \mathrm{MHz}, \mathrm{D}_{2} \mathrm{O}\right)$ of $\mathrm{iQ}[7](\mathrm{A})$ in the absence and in the presence of $(B) 0.2,(C) 0.4,(D) 0.6$, (E) 1.0, (F) 1.6, (G) 2.0 equivalents of $\mathrm{PV}^{2+}$ and $(\mathrm{H})$ neat $\mathrm{PV}^{2+}$ in $\mathrm{D}_{2} \mathrm{O}$ at $20{ }^{\circ} \mathrm{C}$.

resonances is observed as the concentration of $\mathrm{iQ}[7]$ increases, revealing that the chemical exchange between the guest and the $\mathrm{iQ}[7]$ complex is fast compared to the NMR time scale. The chemical shift of the $\alpha$ aromatic protons of $\mathrm{PV}^{2+}$ as a function of the $\mathrm{iQ}[7]$ concentration clearly levels off on addition of 2.0 equivalents of host, suggesting a $2: 1$ (host/guest) stoichiometry for the complex, which we can formulate as 2iQ[7]@ $\mathrm{PV}^{2+}$.

The up-field shifts observed for all the aliphatic proton resonances of $\mathrm{FV}^{2+}$ strongly indicate that the preferred binding sites for $\mathrm{iQ}[7]$ are the terminal aliphatic chains. The resonances for the pentyl moiety of the guest $\mathrm{FV}^{2+}$ shifted up-field by 0.27 , $0.45,0.38$ and $0.36 \mathrm{ppm}$, respectively, from those of the free guest $\mathrm{FV}^{2+}$, indicative of their positioning within the cavity of iQ [7]. In contrast, the signal for the $\beta$ aromatic protons is shifted slightly downfield, while the signal for the $\alpha$ aromatic protons experiences an up-field shift, indicating that the bipyridinium moiety is situated outside the portal of the iQ[7] (Fig. 6).

In the presence of various concentrations of $\mathrm{iQ}[7]$ (Fig. 7), the chemical shifts for all the protons on $\mathrm{HV}^{2+}$ are displaced upfield, a situation very similar to that observed in both the $\mathrm{BV}^{2+}$ and $\mathrm{FV}^{2+}$ cases. The only difference is that the $\beta$ aromatic protons are displaced significantly downfield. These two findings are consistent with the viologen nucleus remaining outside of the host cavity. These experimental observations are consistent with the formation of a $2: 1$ host-guest inclusion complex with two $\mathrm{iQ}[7]$ molecules residing on the aliphatic chains.

${ }^{1} \mathrm{H}$ NMR spectroscopy was also used to monitor the binding behaviour of $\mathrm{iQ}[7]$ with the last guest in the series, namely $\mathrm{SV}^{2+}$. Fig. 8 presents the ${ }^{1} \mathrm{H}$ NMR spectra of $\mathrm{SV}^{2+}$ in $\mathrm{D}_{2} \mathrm{O}$ recorded in the absence as well as in the presence of the host. From Fig. 8, it is evident that in the presence of $\mathrm{iQ}[7]$, the peaks for the alkyl chain protons of $\mathrm{SV}^{2+}$ display substantial up-field shifts and broadening effects compared to the free guest. At the same time, the signal corresponding to the $\beta$-proton of $\mathrm{SV}^{2+}$ shifts slightly downfield, which is characteristic of the protons being located just outside the host's cavity portal. The experimental data indicated that the alkyl chain moiety of the $\mathrm{SV}^{+}$guest was 


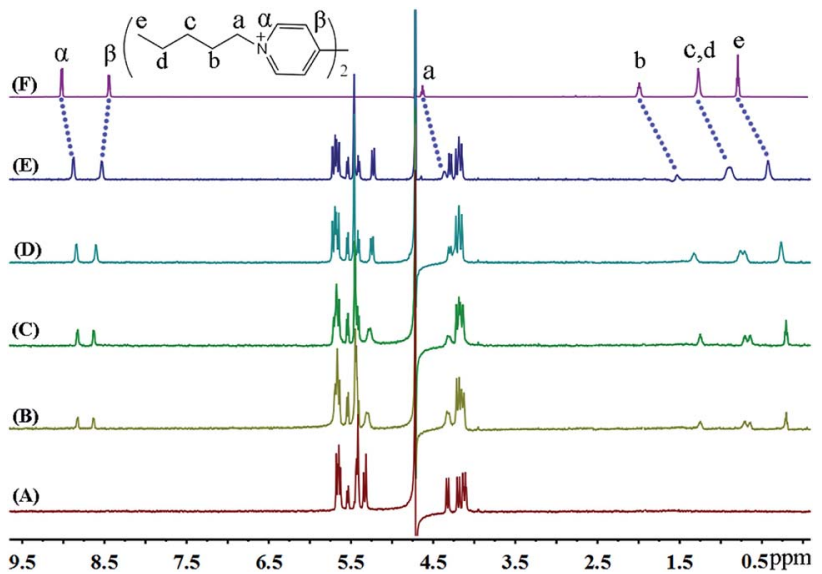

Fig. $6{ }^{1} \mathrm{H}$ NMR spectra $\left(400 \mathrm{MHz}, \mathrm{D}_{2} \mathrm{O}\right)$ of $\mathrm{iQ}[7](\mathrm{A})$ in the absence and in the presence of (B) 0.4 , (C) 1.0, (D) 1.4, (E) 2.0 equivalents of $\mathrm{FV}^{2+}$ and (F) neat $\mathrm{FV}^{2+}$ in $\mathrm{D}_{2} \mathrm{O}$ at $20^{\circ} \mathrm{C}$.

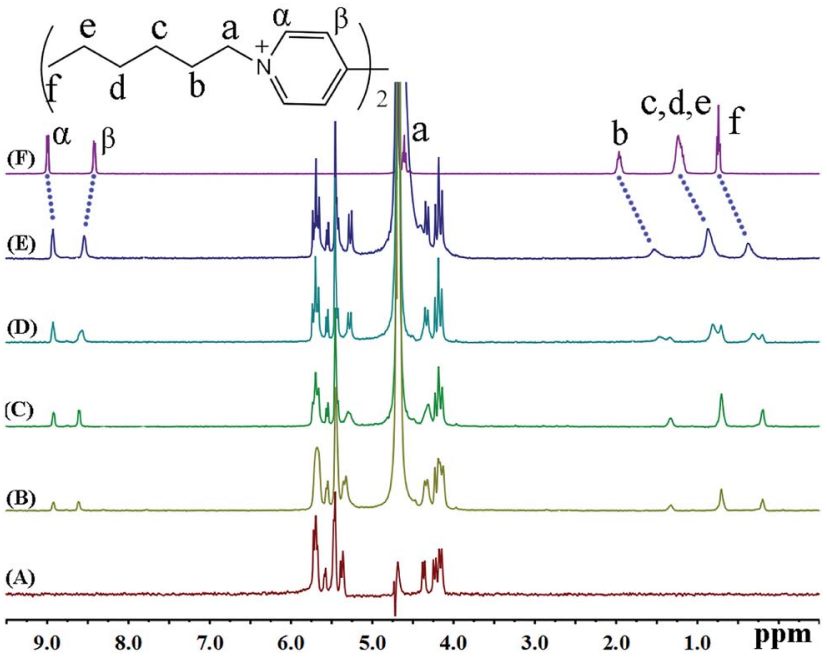

Fig. $7{ }^{1} \mathrm{H}$ NMR spectra $\left(400 \mathrm{MHz}, \mathrm{D}_{2} \mathrm{O}\right)$ of $\mathrm{iQ}$ [7] (A) in the absence and in the presence of (B) 0.3 , (C) 0.8 , (D) 1.4 , (E) 2.0 equivalents of $\mathrm{HV}^{2+}$ and $(\mathrm{F})$ neat $\mathrm{HV}^{2+}$ in $\mathrm{D}_{2} \mathrm{O}$ at $20^{\circ} \mathrm{C}$.

located inside the cavity of the $\mathrm{iQ}[7]$, whilst the bipyridinium group remained outside of the portal of the $\mathrm{iQ}[7]$.

\section{Mass spectrometry}

Further evidence for the formation of inclusion complexes for $\mathrm{iQ}[7]$ and the guests $\mathrm{BPY}^{2+}, \mathrm{MV}^{2+}, \mathrm{EV}^{2+}, \mathrm{PV}^{2+}, \mathrm{BV}^{2+}, \mathrm{FV}^{2+}, \mathrm{HV}^{2+}$, $\mathrm{SV}^{2+}$ was provided by MALDI-TOF mass spectrometry experiments. In their MALDI-TOF mass spectra (Fig. S1-S8, ESI $\dagger$ ), the major signals at $m / z=660.01,674.22,688.24,702.27$ (1283.93), 1297.94, 1311.96, 1326.01, 1340.76, each of which correspond to $\mathrm{BPY}^{2+} @ \mathrm{QQ}[7]$ (calculated 660.58), $\mathrm{MV}^{2+} @ \mathrm{QQ}[7]$ (calculated 674.61), EV ${ }^{2+} @ \mathrm{iQ}[7]$ (calculated 688.63), $\mathrm{PV}^{2+} @ i \mathrm{Q}[7]$ (calculated $702.66(1: 1), 1284.05(1: 2)), \mathrm{BV}^{2+} @ i \mathrm{Q}[7]_{2}$ (calculated 1298.17), $\mathrm{FV}^{2+} @ \mathrm{iQ}[7]_{2}$ (calculated 1312.19), $\mathrm{HV}^{2+} @ \mathrm{QiQ}[7]_{2}$ (calculated 1326.22), SV ${ }^{2+} @ i \mathrm{Q}[7]_{2}$ (calculated 1340.25), respectively, were observed. The intense signals provide direct support for the

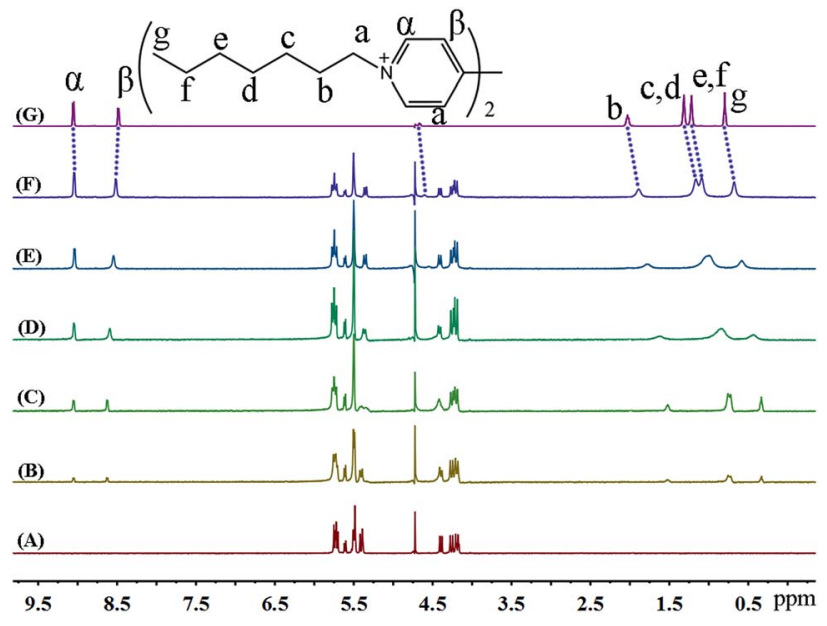

Fig. $8{ }^{1} \mathrm{H}$ NMR spectra $\left(400 \mathrm{MHz}, \mathrm{D}_{2} \mathrm{O}\right)$ of $\mathrm{iQ}[7](\mathrm{A})$ in the absence and in the presence of (B) 0.3, (C) 0.8, (D) 1.4, (E) 1.8, (F) 2.1 equivalents of $\mathrm{SV}^{2+}$ and $(\mathrm{G})$ neat $\mathrm{SV}^{2+}$ in $\mathrm{D}_{2} \mathrm{O}$ at $20^{\circ} \mathrm{C}$.

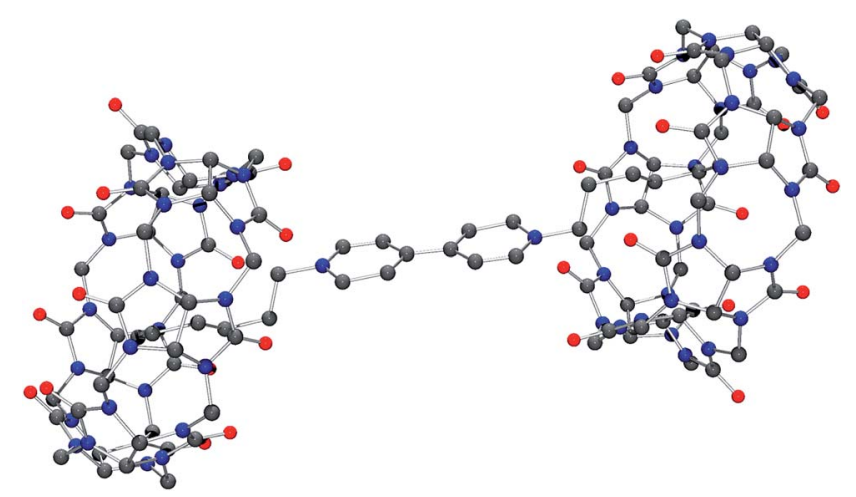

Fig. 9 Molecular structure of $\left[(i Q[7])_{2}(\mathrm{HV})_{2}\right]\left[\mathrm{CdCl}_{3} \mathrm{Br}\right]\left[\mathrm{H}_{3} \mathrm{O}^{+}\right]_{2}\left[\mathrm{H}_{2} \mathrm{O}\right]_{12.5}$.

formation of a $1: 1$ stoichiometry for the host-guest inclusion complexes iQ[7]@BPY ${ }^{2+}, \mathrm{iQ}[7] @ \mathrm{MV}^{2+}, \mathrm{iQ}[7] @ \mathrm{EV}^{2+}, \mathrm{iQ}[7] @ \mathrm{PV}^{2+}$, and $2: 1$ stoichiometry for the host-guest inclusion complexes 2iQ[7]@PV ${ }^{2+}, 2 \mathrm{iQ}[7] @ \mathrm{BV}^{2+}, 2 \mathrm{iQ}[7] @ \mathrm{FV}^{2+}, 2 \mathrm{iQ}[7] @ \mathrm{HV}^{2+}$, $2 \mathrm{iQ}[7] @ \mathrm{SV}^{2+}$.

\section{UV spectroscopy}

To better understand the binding of the symmetric viologens to $\mathrm{iQ}[7]$, we also investigated, by using UV absorption spectroscopy, the interactions between $\mathrm{iQ}[7]$ and the symmetric viologens. A further example appears in more detail in Fig. S10, $\uparrow$ which shows the UV spectra obtained when aqueous solutions containing a fixed concentration of $\mathrm{MV}^{2+}$ and varied concentrations of $\mathrm{iQ}[7]$. On gradually increasing the $\mathrm{iQ}[7]$ concentration in the $\mathrm{MV}^{2+}$ solution, the absorption band associated with the guest $\mathrm{MV}^{2+}$ exhibits a progressive decrease due to the formation of the supramolecular $\mathrm{iQ}[7] @ \mathrm{MV}^{2+}$ complex. The absorbance versus ratio of $n(\mathrm{iQ}[7]) / n\left(\mathrm{MV}^{2+}\right)$ data can be fitted to a $1: 1$ binding model. Similar changes in the absorption spectra of the guests $\mathrm{BPY}^{2+}$ and $\mathrm{EV}^{2+}$ were observed as the $\mathrm{iQ}[7]$ concentration was increased (Fig. S9 and S11, ESI $\dagger$ ). Thus, these guests exhibited similar binding interactions with $\mathrm{iQ}[7]$ for 
which the bipyridinium core of the viologen is embedded in the iQ[7] host. The symmetrical ${ }^{1} \mathrm{H}$ NMR spectra imply that these guests are completely threaded through the host and that the main binding site for the host is the aromatic nucleus of the viologen residue. The UV absorption of the $\mathrm{iQ}[7] @ \mathrm{HV}^{2+}$ system exhibits progressively higher absorbance as the ratio of $n(\mathrm{iQ}[7]) /$ $n\left(\mathrm{HV}^{2+}\right)$ increases, this is different to the $\mathrm{iQ}[7] @ \mathrm{MV}^{2+}$ system. Similar changes in the absorption spectra of the guests $\mathrm{PV}^{2+}$, $\mathrm{BV}^{2+}, \mathrm{FV}^{2+}$ and $\mathrm{SV}^{2+}$ were observed as the $\mathrm{iQ}[7]$ concentration was increased (Fig. S12-S16, ESI $\dagger$ ). The alkyl moiety of the guests were encapsulated into the cavity of the $\mathrm{iQ}[7]$ host, generating a 2 : 1 host-guest inclusion complex. The strong binding of $\mathrm{iQ}[7]$ to the viologens is presumably due to the favourable ion-dipole interactions between the positively charged guest and the portal oxygen atoms of $\mathrm{iQ}[7]$ in addition to hydrophobic effects.

\section{Molecular structure of $\mathrm{iQ}[7]-\mathrm{HV}^{2+}$ and $\mathrm{iQ}[7]-\mathrm{SV}^{2+}$ system}

The structure of $\mathbf{i Q}[7] @ \mathbf{H V}^{2+}$. X-ray quality crystals of the inclusion complex iQ[7]@HV ${ }^{2+}$ were successfully obtained by slow vapour evaporation of aqueous solutions containing the iQ [7] host and the corresponding viologen guest. Single-crystal $\mathrm{X}$-ray diffraction analysis reveals the composition of the compound to be $\left[(\mathrm{iQ}[7])_{2}(\mathrm{HV})_{2}\right]\left[\mathrm{CdCl}_{3} \mathrm{Br}\right]\left[\mathrm{H}_{3} \mathrm{O}^{+}\right]_{2}\left[\mathrm{H}_{2} \mathrm{O}\right]_{12.5}$. In the structure it was not possible to locate hydrogen atoms attached to water, however, the central oxygen atoms can be reliably located. $\mathrm{O} 2 \mathrm{w}$ and $\mathrm{O} 3 \mathrm{w}$ form rather short $\mathrm{O} \cdots \mathrm{O}$ contacts to other water molecules (around 2.45 $\mathrm{A}$ ), and we assign O2w and O3w as the central atoms of $\mathrm{H}_{3} \mathrm{O}^{+}$ions. Other water molecules form longer contacts suggestive of hydrogen bonds between water. The $\mathrm{H}_{3} \mathrm{O}^{+}$is needed for charge balancing (Fig. 9).

Although the structure is obtained from a chloride rich solution there is clear evidence that bromide is present (presumably from the viol ${ }^{2+}\left(\mathrm{Br}^{-}\right)$starting material). Indeed, the refinement is considerably better when bromide is introduced. The overall composition of each anion is thus approximately $\left[\mathrm{CdCl}_{3} \mathrm{Br}\right]^{2-}$. The structure contains a simple primitive array of $\mathrm{iQ}[7]$ rings with $\left[\mathrm{CdCl}_{3} \mathrm{Br}\right]^{2-}$ anions, water and hydronium cations. The viologen cations lie in two different crystallographic positions. One half of the viologen cations are located extra to the viologen cup, but the second set are located such that their alkyl chains are localized within the cup (B-type structure) and each viologen is found between two rings. This iQ-viol-iQ arrangement has a centre of inversion at the centre of the viologen. There are $\mathrm{C}-\mathrm{H} \cdots \mathrm{Cl}$ and $\mathrm{C}-\mathrm{H} \cdots \mathrm{Br}$ interactions between the $\left[\mathrm{CdCl}_{3} \mathrm{Br}\right]^{2-}$ anions and the iQ and also the viologen cations. For the asymmetric unit, see Fig. S25 (ESI†).

The structure of iQ[7]@SV ${ }^{2+}$. Single-crystals of iQ[7]@SV ${ }^{2+}$ were obtained under the same conditions as employed for $\mathrm{iQ}[7]$ (a $\mathrm{HV}^{2+}$, i.e. slow vapour evaporation of an aqueous solution. The structure consists of a simple primitive array of $\mathrm{iQ}[7]$ rings with $\left[\mathrm{CdCl}_{4}\right]^{2-}, \mathrm{SV}^{2+}$ cations, water and hydronium ions to give an overall composition of $(\mathrm{iQ}[7])_{2}(\mathrm{C} 7-\mathrm{SV})_{1.5}\left[\mathrm{CdCl}_{4}\right]_{4}$ $\left(\mathrm{H}_{3} \mathrm{O}^{+}\right)_{5}\left(\mathrm{H}_{2} \mathrm{O}\right)_{8}$ or alternatively this could be written as (iQ $[7])_{4}(\mathrm{C} 7-\mathrm{SV})_{3}\left[\mathrm{CdCl}_{4}\right]_{8}\left(\mathrm{H}_{3} \mathrm{O}^{+}\right)_{10}\left(\mathrm{H}_{2} \mathrm{O}\right)_{16}$, which reflects the fact that one of the $\mathrm{C} 7-\mathrm{SV}$ cations sits on an inversion centre. The $\mathrm{H}_{3} \mathrm{O}^{+}$is needed for charge balancing; protons were not located

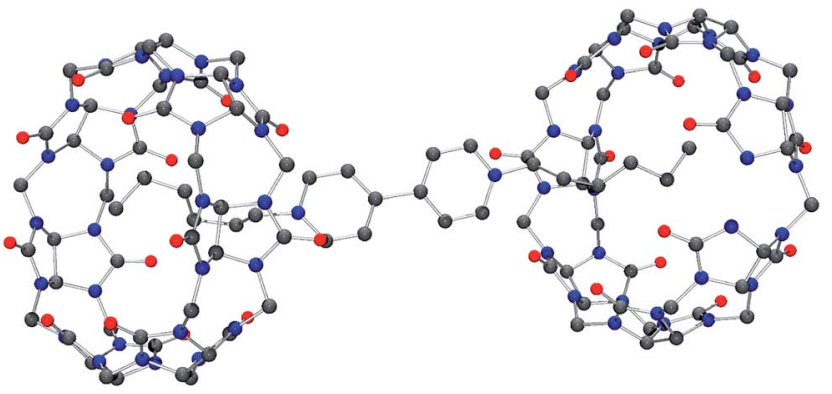

Fig. 10 Molecular structure of the C7-SV cation bridging two iQ[7].

crystallographically on the water or hydronium ions. The structure was treated with the SQUEEZE routine to model disordered water contained within the structure and the formula reflects the composition obtained from SQUEEZE. The $\mathrm{C7}-\mathrm{SV}$ resides in two different positions within the structure. One complete C7-SV is located without the $\mathrm{iQ}[7]$ units, whilst a second is positioned such that it forms a type $\mathbf{B}$ inclusion complex (see Fig. 10). This second SV cation is located at an inversion centre and is disordered over it; this disorder was modelled using standard techniques. It is obvious from the disorder and the displacement parameters of the alkyl chain that there is no strong attraction between $\mathrm{iQ}[7]$ and the alkyl chain of C6-SV. Furthermore we have not been able to locate reliably the terminal carbon atom of the alkyl chain.

\section{Isothermal titration calorimetry}

After examining a plausible binding model and establishing the stoichiometry of the complexes formed between $\mathrm{iQ}[7]$ and viologens, we proceeded to determine the binding constants $(K)$ and associated thermodynamic parameters for the viologens binding to $\mathrm{iQ}[7]$ by ITC (Fig. S17-S24, ESI $\dagger$ ). According to the data in Table 1, the iQ[7]-dialkyl-4,4'-bipyridinium dicationic/ guest interactions are exothermic reactions, and the enthalpies gradually increase on increasing the length of the alkyl chains of the symmetric viologen guests. Furthermore, the entropies gradually decrease on increasing the length of the alkyl chains of the symmetric viologen guests.

A number of weak non-covalent interactions can occur between the $\mathrm{iQ}[7]$ host and these symmetric viologen guests. Hydrogen bonds and van der Waals interactions are the main contributions to the enthalpy changes, whilst electrostatic interactions and desolvation effects contribute to the entropy changes. In general, the entropies gradually decrease on increasing the length of the alkyl chains of the symmetric viologen guests. This phenomenon can be explained in terms of the larger occupied volume associated with the 4,4'-bipyridine in the A-type structure versus that of the alkyl chain in the B-type. This could also be viewed in terms of the number of components in play, with two utilized in forming the A-type structure versus three components for the B-type. As revealed in Table 1, all the intermolecular complexations between the $\mathrm{iQ}[7]$ host and the symmetric viologen guests are driven by favourable enthalpy changes, accompanied by either small positive (favorable) or negative (unfavorable) entropy changes. The 
Table 1 ITC measurements of the thermodynamics of iQ[7] dialkyl-4,4'-bipyridinium dicationic guest interactions

\begin{tabular}{|c|c|c|c|c|c|}
\hline Alkyl viologens & $K_{\mathrm{a}}\left(\mathrm{M}^{-1}\right)$ & $\Delta H\left(\mathrm{~kJ} \mathrm{~mol}^{-1}\right)$ & $n$ & $T \Delta S\left(\mathrm{~kJ} \mathrm{~mol}^{-1}\right)$ & $K_{\mathrm{d}}(\mathrm{M})$ \\
\hline $\mathrm{BPY}^{2+}$ & $(1.69 \pm 0.42) \times 10^{5}$ & $-14.89 \pm 0.80$ & $0.996 \pm 0.034$ & 14.94 & $5.920 \times 10^{-6}$ \\
\hline $\mathrm{MV}^{2+}$ & $(7.34 \pm 0.77) \times 10^{3}$ & $-27.55 \pm 9.35$ & $0.976 \pm 0.194$ & -5.49 & $1.363 \times 10^{-4}$ \\
\hline $\mathrm{PV}^{2+}$ & $(1.57 \pm 0.23) \times 10^{5}$ & $-31.90 \pm 1.24$ & $0.523 \pm 0.010$ & -2.24 & $6.381 \times 10^{-6}$ \\
\hline $\mathrm{BV}^{2+}$ & $(1.02 \pm 0.14) \times 10^{5}$ & $-40.66 \pm 2.25$ & $0.470 \pm 0.011$ & -12.05 & $9.760 \times 10^{-6}$ \\
\hline $\mathrm{FV}^{2+}$ & $(4.09 \pm 0.37) \times 10^{5}$ & $-47.86 \pm 0.94$ & $0.534 \pm 0.005$ & -15.82 & $2.446 \times 10^{-6}$ \\
\hline
\end{tabular}

conclusion from this data is that the hydrogen bonding and the van der Waals interactions are the main driving forces for these complexations. It should be noted that at this stage the underlying reasons for the exceptional performance (in terms of enthalpy) when using C1 are unknown.

\section{Conclusions}

In summary, we have investigated the binding interactions of iQ [7] with a series of dialkyl-viologen dicationic guests using ${ }^{1} \mathrm{H}$ NMR spectroscopy, isothermal titration calorimetry and X-ray crystallography. In aqueous solution $\left(\mathrm{D}_{2} \mathrm{O}\right)$, the aromatic nuclei of $\mathrm{BPY}^{2+}, \mathrm{MV}^{2+}$ and $\mathrm{EV}^{2+}$ were partially encapsulated into the $\mathrm{iQ}[7]$ host, giving rise to $1: 1$ binary inclusion complexes. To the best of our knowledge, this is the first systematic investigation on the interactions of $\mathrm{iQ}[7]$ hosts with dialkyl-4,4'-bipyridinium guests. In contrast to this finding, with the longer chain viologens $\left(\mathrm{PV}^{2+}\right.$, $\mathrm{BV}^{2+}, \mathrm{FV}^{2+}, \mathrm{HV}^{2+}$ and $\mathrm{SV}^{2+}$, only the alkyl chains were embedded in the cavity of the $\mathrm{iQ}[7]$ host, forming $2: 1$ ternary complexes. These findings suggest that the inclusion of the aliphatic chains is favoured compared to inclusion of the aromatic bipyridinium group. In the presence of $\mathrm{CdCl}_{2}$, the guest $\mathrm{HV}^{2+}$ and $\mathrm{SV}^{2+}$ form a pseudorotaxane with $\mathrm{iQ}[7]$ hosts in the solid state.

\section{Experimental section}

All ${ }^{1} \mathrm{H}$ NMR spectra, including those for the titration experiments, were recorded at $20{ }^{\circ} \mathrm{C}$ on a VARIAN INOVA-400 spectrometer. $\mathrm{D}_{2} \mathrm{O}$ was used as a field-frequency lock, and the observed chemical shifts are reported in parts per million (ppm). MALDI-TOF mass spectrometry was recorded on a Bruker BIFLEX III ultra-high resolution Fourier transform ion cyclotron resonance (FT-ICR) mass spectrometer with a-cyano4-hydroxycinnamic acid as matrix. Absorption spectra of the host-guest complexes were performed with an Aglient 8453 spectrophotometer at room temperature. The host and guests were dissolved in deionized water. UV-visible spectra was obtained at a concentration of $2.00-4.00 \times 10^{-5} \mathrm{~mol} \mathrm{~L}^{-1}$ guest and different iQ[7] concentrations for the iQ[7]@guest system.

Starting materials and solvents for syntheses were purchased commercially and used as supplied without further purification. $\mathrm{iQ}[7]$ was prepared and purified according to our previously published procedure. ${ }^{13}$ With the exception of methyl viologen and $N, N^{\prime}$-diheptyl-4,4'-bipyridinium dibromide (Aldrich), all other viologen guests were prepared by the treatment of $4,4^{\prime}$-bipyridine with an excess of the corresponding alkyl bromide. The general procedure for the synthesis of (dialkyl) viologens is as follows: a mixture of $4,4^{\prime}$-dipyridyl (1.0 equiv.) and the corresponding alkyl bromide ( 6 equiv.) were refluxed for $3 \mathrm{~h}$. The resulting precipitate was filtered, and then loaded onto a silica gel (G200) column, eluted with a $3: 1$ acetone : acetic acid mixture and the second major species eluted was collected. The eluate was reduced in vacuo to a small volume, separated, and recrystallized from a solvent system comprising 1:2 ethanol : ether. The crystals were collected, washed with ether, and air-dried.

${ }^{1} \mathrm{H}$ NMR (400 MHz, $\left.\mathrm{D}_{2} \mathrm{O}\right): \mathrm{EV}^{2+} \delta 9.04(\mathrm{~d}, J=5.2 \mathrm{~Hz}, 4 \mathrm{H}, \alpha$ of viologen), 8.45 (d, $J=4.4 \mathrm{~Hz}, 4 \mathrm{H}, \beta$ of viologen), 4.67 (q, $J=$ $\left.6.0 \mathrm{~Hz}, 4 \mathrm{H},-\mathrm{CH}_{2}-\right), 1.61\left(\mathrm{t}, J=5.8 \mathrm{~Hz}, 6 \mathrm{H},-\mathrm{CH}_{3}\right) \mathrm{ppm}^{-\mathrm{PV}^{2+} \delta} 9.01$ $(\mathrm{d}, J=4.8 \mathrm{~Hz}, 4 \mathrm{H}, \alpha$ of viologen), $8.43(\mathrm{~d}, 4.4 \mathrm{H}, \beta$ of viologen $), 4.59$ $\left(\mathrm{t}, J=6.0 \mathrm{~Hz}, 4 \mathrm{H},-\mathrm{CH}_{2}-\right), 1.99\left(\mathrm{~m}, 4 \mathrm{H},-\mathrm{CH}_{2}-\right), 0.88(\mathrm{t}, J=6.0 \mathrm{~Hz}$, $\left.6 \mathrm{H},-\mathrm{CH}_{3}\right) ; \mathrm{BV}^{2+} \delta 9.01(\mathrm{~d}, J=4.8 \mathrm{~Hz}, 4 \mathrm{H}, \alpha$ of viologen), $8.43(\mathrm{~d}, J$ $=4.4 \mathrm{~Hz}, 4 \mathrm{H}, \beta$ of viologen $), 4.62\left(\mathrm{t}, J=5.6 \mathrm{~Hz}, 4 \mathrm{H},-\mathrm{CH}_{2}-\right), 1.96$ $\left(\mathrm{m}, 4 \mathrm{H},-\mathrm{CH}_{2}-\right), 1.30\left(\mathrm{~m}, 4 \mathrm{H},-\mathrm{CH}_{2}-\right), 0.86(\mathrm{t}, J=6.0 \mathrm{~Hz}, 6 \mathrm{H}$, $\left.-\mathrm{CH}_{3}\right) ; \mathrm{FV}^{2+} \delta 9.02(\mathrm{~d}, J=6.0 \mathrm{~Hz}, 4 \mathrm{H}, \alpha$ of viologen), 8.44 (d, $J=$ $5.2 \mathrm{~Hz}, 4 \mathrm{H}, \beta$ of viologen), $4.63\left(\mathrm{t}, J=6.0 \mathrm{~Hz}, 4 \mathrm{H},-\mathrm{CH}_{2}-\right), 1.99(\mathrm{~m}$, $\left.4 \mathrm{H},-\mathrm{CH}_{2}-\right), 1.27\left(\mathrm{~m}, 8 \mathrm{H},-\mathrm{CH}_{2}-\right), 0.75\left(\mathrm{t}, J=6.4 \mathrm{~Hz}, 6 \mathrm{H},-\mathrm{CH}_{3}\right)$; $\mathrm{HV}^{2+} \delta 9.02(\mathrm{~d}, J=5.2 \mathrm{~Hz}, 4 \mathrm{H}, \alpha$ of viologen $), 8.44(\mathrm{~d}, J=5.2 \mathrm{~Hz}$, $4 \mathrm{H}, \beta$ of viologen), $4.59\left(\mathrm{t}, J=6.0 \mathrm{~Hz}, 4 \mathrm{H},-\mathrm{CH}_{2}-\right), 1.93(\mathrm{~m}, 4 \mathrm{H}$, $\left.-\mathrm{CH}_{2}-\right), 1.18\left(\mathrm{~m}, 12 \mathrm{H},-\mathrm{CH}_{2}-\right), 0.79\left(\mathrm{t}, J=6.4 \mathrm{~Hz}, 6 \mathrm{H},-\mathrm{CH}_{3}\right)$.

\section{Isothermal titration calorimetry experiments}

The association constants and thermodynamic parameters for the inclusion complexations of alkyl viologens with $\mathrm{iQ}[7]$ were determined by titration calorimetry with an ITC instrument. The heat evolved was recorded at $298.15 \mathrm{~K}$. An aqueous solution $(0.1 \mathrm{mM})$ of $\mathrm{iQ}[7]$ was placed in the sample cell $(1.3 \mathrm{~mL})$. As a solution $(1 \mathrm{mM})$ of the guests $\mathrm{BPY}^{2+}, \mathrm{MV}^{2+}$ and $\mathrm{EV}^{2+}$ was added in a series of 25 injections $(10 \mu \mathrm{L})$. As a solution $(1 \mathrm{mM})$ of the guest $\mathrm{PV}^{2+}$ was added in a series of 25 injections $(6 \mu \mathrm{L})$. As a solution $(1 \mathrm{mM})$ of the guests $\mathrm{BV}^{2+}, \mathrm{FV}^{2+}, \mathrm{HV}^{2+}$ and $\mathrm{SV}^{2+}$ was added in a series of 25 or 20 injections $(4 \mu \mathrm{L})$. The heat of dilution was corrected by injecting the guest solution into deionized water and subtracting these data from those of the host-guest titration. Computer simulations (curve fitting) were performed using the Nano ITC analyze software.

\section{Preparation of iQ[7]@HV ${ }^{2+}$ and iQ[7]@SV ${ }^{2+}$}

To a solution of $N, N^{\prime}$-dihexyl-4,4'-bipyridinium dibromide $\left(\mathrm{HV}^{2+} \cdot 2 \mathrm{Br}^{-} 14.5 \mathrm{mg}, 0.03 \mathrm{mmol}\right)$ and $\mathrm{CdCl}_{2} \cdot 2.5 \mathrm{H}_{2} \mathrm{O}(11.9 \mathrm{mg}, 0.05$ 
$\mathrm{mmol}$ ) in $2 \mathrm{~mL} 3 \mathrm{M} \mathrm{HCl}$ solution, iQ[7] (10.8 mg, $0.008 \mathrm{mmol})$ was added. The resulting reaction mixture was stirred for $5 \mathrm{~min}$ at $50^{\circ} \mathrm{C}$. After cooling to room temperature, the mixture was filtered. Slow solvent evaporation of the filtrate in air over a period of about three weeks provided rhombic colorless crystals of complex $\mathrm{iQ}[7] @ \mathrm{HV}^{2+}$.

To a solution of $N, N^{\prime}$-diheptyl-4, $4^{\prime}$-bipyridinium dibromide $\left(\mathrm{SV}^{2+} \cdot 2 \mathrm{Br}^{-} 10.3 \mathrm{mg}, 0.02 \mathrm{mmol}\right)$ and $\mathrm{CdCl}_{2} \cdot 2.5 \mathrm{H}_{2} \mathrm{O}(10.6 \mathrm{mg}$, $0.04 \mathrm{mmol}$ ) in $2 \mathrm{~mL} 3 \mathrm{M} \mathrm{HCl}$ solution, iQ[7] (10.8 mg, 0.008 $\mathrm{mmol}$ ) was added. The resulting reaction mixture was stirred for $5 \mathrm{~min}$ at $50{ }^{\circ} \mathrm{C}$. After cooling to room temperature, the mixture was filtered. Slow solvent evaporation of the filtrate in air over a period of about three weeks provided rhombic colorless crystals of complexiQ[7]@SV ${ }^{2+}$.

\section{Single-crystal X-ray crystallography}

Single crystals of complex iQ[7]@ $\mathrm{HV}^{2+}$ and $\mathrm{iQ}[7] @ \mathrm{SV}^{2+}$ were grown from $3 \mathrm{M} \mathrm{HCl}$ solution containing $\mathrm{CdCl}_{2}$ salt by slow evaporation. Diffraction data of complex $\mathrm{iQ}[7] @ \mathrm{HV}^{2+}$ was collected at $293 \mathrm{~K}$ with a Bruker SMART Apex-II CCD diffractometer using graphitemonochromated Mo-K $\alpha$ radiation $(\lambda=0.71073 \AA$ A $)$; see Table 2 . Diffraction data of complex $\mathrm{iQ}[7] @ \mathrm{SV}^{2+}$ was collected using an Agilent Technologies Xcalibur diffractometer with an enhance $(\mathrm{Cu})$ source and an Eos detector in a series of $\omega$-scans. Empirical

Table 2 Crystal data and structural information for iQ[7]@ $\mathrm{HV}^{2+}$ and $\mathrm{iQ}$ [7] $\mathrm{aSV}^{2+}$

\begin{tabular}{lll}
\hline Compound & $\mathrm{iQ}[7] @ \mathrm{HV}^{2+}$ & $\mathrm{iQ}[7] @ \mathrm{SV}^{2+}$ \\
Formula & $\mathrm{C}_{64} \mathrm{H}_{74} \mathrm{Br}_{2.09} \mathrm{Cd}_{2}$ & $\mathrm{C}_{59} \mathrm{H}_{74} \mathrm{Cd}_{2} \mathrm{Cl}_{8}$ \\
& $\mathrm{Cl}_{5.91} \mathrm{~N}_{30} \mathrm{O}_{26.50}$ & $\mathrm{~N}_{29.50} \mathrm{O}_{18}$ \\
Formula weight & 2288.88 & 1918.29 \\
Crystal system & Monoclinic & Monoclinic \\
Space group & $P 2_{1} / c$ & $P 2_{1} / c$
\end{tabular}

\section{Unit cell dimensions}

$\begin{array}{lll}a(\AA) & 17.5609(8) & 17.8377(5) \\ b(\AA) & 26.6596(13) & 26.1661(9) \\ c(\AA) & 19.7774(9) & 19.5368(9) \\ \alpha(\AA) & 90 & 90 \\ \beta(\AA) & 96.521(2) & 98.161(3) \\ \gamma(\AA) & 90 & 90 \\ V\left(\AA^{3}\right) & 9199.2(7) & 11215.2(15) \\ Z & 4 & 4 \\ \text { Temperature }(\mathrm{K}) & 293(2) & 296(2) \\ \text { Wavelength }(\AA) & 0.71073 & 0.71073 \\ \text { Calculated density }\left(\mathrm{Mg} \mathrm{m}^{-3}\right) & 1.653 & 1.412 \\ \text { Absorption coefficient }\left(\mathrm{mm}^{-1}\right) & 1.631 & 0.781 \\ \text { Transmission factors } & 0.615 \text { and } 1.324 & 0.940 \text { and } 0.993 \\ (\text { min/max) } & & \\ \left.\text { Crystal size (mm }{ }^{3}\right) & 0.27 \times 0.24 \times 0.23 & 0.26 \times 0.22 \times 0.21 \\ \theta\left(\text { max) }\left({ }^{\circ}\right)\right. & 26.0 & 25.0 \\ \text { Reflections measured } & 83045 & 89604 \\ \text { Unique reflections } & 17846 & 15902 \\ R_{\text {int }} & 0.0606 & 0.1174 \\ \text { Reflections with } F^{2}>2 \sigma\left(F^{2}\right) & 17846 & 15902 \\ \text { Number of parameters } & 1183 & 954 \\ R_{1}\left[F^{2}>2 \sigma\left(F^{2}\right)\right] & 0.0512 & 0.1119 \\ \text { w } R_{2}(\text { all data) } & 0.1548 & 0.3802 \\ \text { GOOF, } S & 1.027 & 1.042 \\ \text { Largest difference } & 1.148 \text { and }-0.763 & 2.098 \text { and }-1.598 \\ \text { peak and hole }\left(\mathrm{e} \AA^{-3}\right) & & \end{array}$

absorption corrections were performed by using the multiscan program SADABS. Structural solution and full-matrix least-squares refinement based on $F^{2}$ were performed with the SHELXS-2014 and SHELXL-2014 program packages, respectively. All nonhydrogen atoms were treated anisotropically in all cases. All hydrogen atoms were introduced as riding atoms with an isotropic displacement parameter equal to 1.2 times that of the parent atom.

\section{Acknowledgements}

Financial support from the Natural Science Foundation of China (21561007), the Innovation Program for High-level Talents of Guizhou Province (2016-5657) and the Science and Technology Fund of Guizhou Province (2016-1030) is gratefully acknowledged. CR thanks the EPSRC for a travel grant.

\section{References}

1 (a) X. L. Ni, X. Xiao, H. Cong, L. L. Liang, K. Chen, X. J. Cheng, N. N. Ji, Q. J. Zhu, S. F. Xue and Z. Tao, Chem. Soc. Rev., 2013, 42, 9480-9508; (b) X. L. Ni, X. Xiao, H. Cong, Q. J. Zhu, S. F. Xue and Z. Tao, Acc. Chem. Res., 2014, 47, 1386-1395.

2 (a) L. Isaacs, S. K. Park, S. Liu, Y. K. Ko, N. Selvapalam, Y. Kim, H. Kim, P. Y. Zavalij, G. H. Kim, H. S. Lee and K. Kim, J. Am. Chem. Soc., 2005, 127, 18000-18001; (b) S. Liu, K. Kim and L. Isaacs, J. Org. Chem., 2007, 72, 6840-6847; (c) L. D. Isaacs, S. M. Liu, K. Kim, S. K. Park, Y. H. Ko, H. Kim, Y. Kim and N. Selvapalam, Introverted cucurbituril compounds and their preparation, crystal structure and binding properties, PCT Int. Appl., 2007, 48-51; (d) R. V. Pinjari and S. P. Gejji, J. Phys. Chem. A, 2009, 113, 1368-1376; (e) Q. Li, S. C. Qiu, Y. Q. Zhang, S. F. Xue, Z. Tao, T. J. Prior, C. Redshaw, Q. J. Zhu and X. Xiao, RSC Adv., 2016, 6, 77805-77810; (f) S. C. Qiu, Q. Li, K. Chen, Y. Q. Zhang, Q. J. Zhu and Z. Tao, Inorg. Chem. Commun., 2016, 72, 50-53.

3 P. Monk, The Viologens: Physicochemical Properties, Synthesis and Applications of the Salts of 4,4'-Bipyridine, New York, 1998.

4 W. Ong, M. Gómez-Kaifer and A. E. Kaifer, Org. Lett., 2002, 4, 1791-1794.

5 W. Ong and A. E. Kaifer, Angew. Chem., Int. Ed., 2003, 42, 2164-2167. 6 K. Moon and A. E. Kaifer, Org. Lett., 2004, 6, 185-188.

7 V. Sindelar, K. Moon and A. E. Kaifer, Org. Lett., 2004, 6, 2665-2668.

8 Y. Ling, J. T. Mague and A. E. Kaifer, Chem.-Eur. J., 2007, 13, 7908-7914.

9 B. Cheng and A. E. Kaifer, Langmuir, 2015, 31, 2997-3002.

10 A. E. Kaifer, Acc. Chem. Res., 2014, 47, 2160-2167.

11 (a) R. L. Lin, J. Q. Li, J. X. Liu and A. E. Kaifer, J. Org. Chem., 2015, 80, 10505-10511; (b) Q. Liu, Q. Li, X. J. Cheng, Y. Y. Xi, B. Xiao, X. Xiao, Q. Tang, Y. Huang, Z. Tao, S. F. Xue, Q. J. Zhu and J. X. Zhang, Chem. Commun., 2015, 51, 9999-10001.

12 Q. Li, S. C. Qiu, J. H. Liu, S. F. Xue, X. Xiao, Z. Tao and Q. J. Zhu, RSC Adv., 2015, 5, 68914-68918.

13 Q. Li, Y. Q. Zhang, Q. J. Zhu, S. F. Xue, Z. Tao and X. Xiao, Chem.-Asian J., 2015, 10, 1159-1164. 